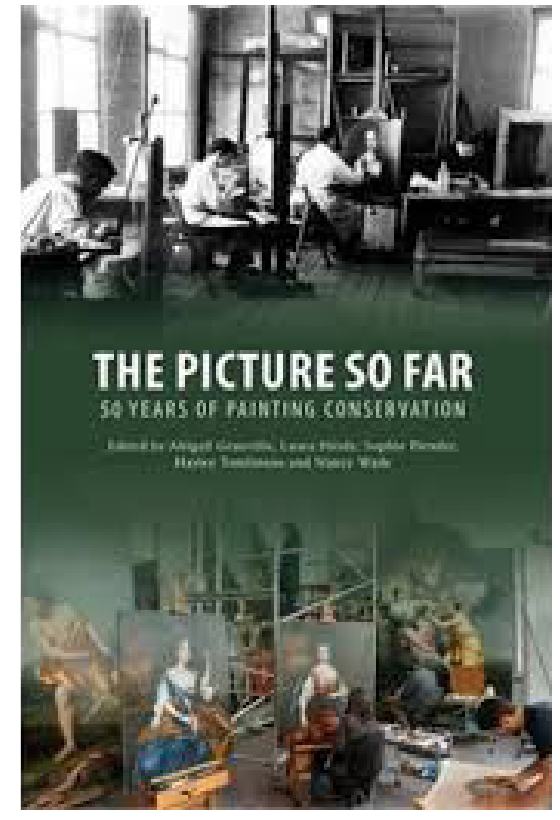

\section{The Picture so Far: 50 Years of Painting Conservation}

Abigail Granville, Laura Hinde, Sophie Plender, Hayley Tomlinson, Nancy Wade (eds)

London: Archetype Publications Ltd, 2017

ISBN: 9781909492240

Dimensiones: $6.3 \times 0.5 \times 9.3$

Páginas: 156

llustraciones en color
Si hubiera que definir The Picture so Far en pocas palabras, podríamos referirnos a él como un revelador paseo por la historia, los hitos y los personajes más relevantes de la práctica de la conservación-restauración de las últimas décadas, concretamente centrado en el entorno anglosajón. Esta publicación nace, de hecho, a partir de la celebración de la conferencia con el mismo título organizada por Asociación Británica de ConservadoresRestauradores (BAPCR) en la Royal Institution de Londres, en la que se dieron cita 180 profesionales de diversos ámbitos de la conservación-restauración; singularmente, esta cita se organizó coincidiendo con el 50 aniversario de la fundación del estudio privado de restauración de D. Bull y R. Shepherd, dos importantes restauradores británicos que durante años habían trabajado para la National Gallery de Londres.

Algunas de las personalidades más relevantes de la conservación-restauración de la última mitad del siglo $X X$ intervienen en esta publicación, abordando aspectos relevantes de la evolución de acontecimientos y criterios, los cambios en la noción de pátina, la influencia de los avances de la ciencia y la tecnología en la práctica de la conservación, el desarrollo de los sistemas acuoso de limpieza, la importancia de archivos, historia oral y documentos fílmicos y el papel de las réplicas, entre otros.

Así, a modo de inicio, el célebre David Bomford, restaurador de pintura de la National Gallery de Londres y actual director de conservación del Museo de Bellas Artes de Boston, presenta un texto sobre los "tres días que cambiaron la conservación", en referencia al enorme impacto (tanto en los postulados teóricos como en su aplicación práctica, así como en el debate ideológico posterior) de la conferencia sobre reentelados acaecida en Greenwich en 1974.

Por su parte, Joyce Hill Stoner, directora de los estudios de doctorado sobre conservación de la Universidad de Delaware y una de las figuras más relevantes en el entorno anglosajón, aborda una interesante revisión sobre los grandes pioneros de la conservación-restauración de las últimas décadas y su legado en la práctica de la restauración, tomando como punto de vista el proyecto de la Historia Oral sobre la Conservación de la FAIC (Fundación del Instituto Americano de Conservación).

Resulta también de gran interés el texto de Aviva Burnstock, directora del Departamento de Conservación y Tecnología del Instituto de Arte Courtauld, una de las instituciones educativas británicas más antiguas y relevantes del ámbito de la conservación-restauración; en éste, la autora repasa las contribuciones de las diferentes técnicas de examen y análisis a la mejora del conocimiento sobre la práctica artística y sobre los cambios producidos en las obras por efecto del envejecimiento, $y$, en definitiva, cómo esta formación científica y tecnológica ha ejercido una gran influencia en el propio desarrollo de la profesión durante últimos cincuenta años.

Desde su texto, Richard Wolbers, profesor asociado del Departamento de Conservación de Arte de la Universidad de Delaware y figura fundamental para el desarrollo de los métodos acuosos de limpieza, incide en el valor de la ciencia, la formación especializada materializada en 
forma de talleres prácticos y el intercambio de ideas a nivel internacional en el mundo actual, ideas principales de su texto dedicado a la evolución histórica de estos sistemas de limpieza durante el periodo comprendido entre 1984 y 2014.

Muy reveladora resulta también la aportación de Salvador Muñoz-Viñas sobre la evolución del concepto de pátina, uno de los elementos más controvertidos en el ámbito de la Teoría de la Restauración. Haciendo un paralelismo entre el sentido y la sensibilidad o, en sus palabras, entre los "patinófilos" y los "patinofóbicos", Muñoz Viñas plantea incluso una herramienta en forma de lúdico cuestionario que nos permite situar nuestra percepción personal sobre la pátina en estos mismos términos.

La monografía se completa con otros textos relativos al empleo de réplicas o maquetas como herramienta de conservación preventiva y a la importancia de los archivos y documentos fílmicos, entre otros, completando una interesante publicación en la que sin duda el lector encontrará esclarecedoras claves para el estudio de la conservación-restauración de la época más reciente.

Silvia Garcia Fernandez-Villa Facultad de Bellas Artes (UCM) 